\title{
Peningkatan Akurasi Lokasi Gempa Mikro Dengan Menggunakan Metoda Double-Difference Dan Korelasi Silang Master Waveform
}

\author{
A. Hijriani ${ }^{1}$, D. P. Sahara ${ }^{2}$, A. D. Nugraha ${ }^{2}$, I. Ramadhan ${ }^{3}$, R. P. Sidik ${ }^{3}$ \\ ${ }^{1}$ Departemen Teknik Geofisika, Institut Teknologi Bandung, Ganesa 10, Bandung 40132, Jawa Barat, Indonesia \\ ${ }^{2}$ Kelompok Keahlian Geofisika Global, Institut Teknologi Bandung, Ganesa 10, Bandung 40132, Jawa Barat, Indonesia \\ ${ }^{3}$ PT. Supreme Energy, Menara Sentraya Floor 23th, Iskandarsyah Raya 2, Jakarta, Indonesia. \\ Email. arifahijriani@gmail.com \\ Rekam jejak artikel:
}

Diterima: 01 Nov 2017; Direvisi: 08 Nov 2017; Disetujui: 09 Nov 2017

\begin{abstract}
Abstrak: Perekaman gempa mikro menjadi suatu metode yang umum dilakukan untuk memperkirakan struktur geologi pada suatu lapangan panas bumi. Data hasil perekaman gempa mikro di Lapangan Panas Bumi ARD, sebelum proses pemboran eksplorasi, diolah dan dianalisis dalam penelitian ini dengan tujuan untuk memetakan struktur bawah permukaan. Jaringan seismik pada Lapangan Panas Bumi ARD terdiri dari 26 stasiun yang dipasang selama 8 bulan sejak Agustus 2011 dalam radius $20 \mathrm{~km}$ dari target reservoir. Terdapat 637 gempa mikro lokal yang berhasil terdeteksi dan terpetakan selama pengukuran berlangsung. Jumlah ini relatif besar untuk sebuah daerah yang masih dalam dan terpetakan selama pengukuran berlangsung. Jumlah ini relatif besar untuk sebuah daerah yang masih dalam mengingat keberadaan kesalahan penentuan waktu tiba dan model kecepatan. Studi ini bertujuan untuk meminimalkan kesalahan akibat dua parameter tersebut dengan menggunakan metode korelasi silang dan double difference. Korelasi silang waveform dengan master event diterapkan untuk meningkatkan kualitas penentuan waktu tiba. Terdapat 559 dan 527 pasangan waveform yang memiliki korelasi diatas 0.76. Gempa-gempa mikro yang muncul diinterpretasikan berasal dari bidang patahan yang sama. Koreksi waktu tiba rata-rata yang dihasilkan adalah sebesar 0.2 detik. Setelah dilakukan relokasi dengan metode double difference, lokasi gempa bergeser sekitar 200 hingga $1500 \mathrm{~m}$ dan dihasilkan cluster gempa mikro yang lebih tajam. Kluster gempa mikro tersebut bersesuaian dengan struktur berarah Timur laut - Barat daya di lapangan ARD. Residual travel time gan hasil penelitian dapat disimpulkan bahwa relokasi hiposenter dengan metode korelasi silang master event dan double hasil penelitian dapat disimpulkan bahwa relokasi hiposenter dengan metode kor

Kifference berhasil mereduksi ketidakpastian lokasi hiposenter di lapangan ARD.

Abstract: Currently, the microseismic method becomes the main procedure in inferring the geological structure of a geothermal reservoir. This study maximizes the seismic network of the ARD Geothermal Field prior to drilling to
undertake the mapping of subsurface structures. The seismic network in this field has 26 stations that have been installed for 8 months from August 2011 to May 2012 within a $20 \mathrm{~km}$ radius of the reservoir target. There were 637 local micro-earthquakes that were successfully detected and mapped during the measurement. This amount is large enough for an area that is still in the early stages of geothermal exploration. However, often the accuracy of the location of the hypocenter still needs to be improved due to the error in the arrival time picking and velocity model. This study aims to minimize errors due to these two parameters by using the method of master event cross-correlation and double difference. Cross-correlation waveform with a master event is applied to improve the arrival time picking quality. There are 559 and 527 waveform pairs of $P$ and $S$ wave, respectively, with correlations correction is 0.2 seconds. After relocation by double difference method, the location of the earthquake shifted about correction is 0.2 seconds. After relocation by double difference method, the location of the earthquake shifted about 200 to $1500 \mathrm{~m}$ and generated a sharper cluster of microearthquakes. The earthquake cluster corresponds to the
structure with the orientation of $N E-S W$ in ARD. Residual travel time earthquake also showed a significant decrease. structure with the orientation of $N E-S W$ in ARD. Residual travel time earthquake also showed a significant decrease. in reducing the uncertainty of hypocenter location in ARD. This method can also be applied to other geothermal fields.

Keywords: Microseismic, Waveform cross-correlation, Geothermal exploration, Double difference relocation
\end{abstract}

\section{PENDAHULUAN}

Indonesia adalah negara dengan perkiraan cadangan panas bumi yang tinggi. Hal ini adalah akibat banyaknya gunung api di Indonesia sehingga memungkinkan banyak sistem panas bumi terbentuk. Gunung api yang terbentuk akibat proses subduksi juga memberikan efek lain bagi Indonesia, yaitu hampir seluruh daerah di Indonesia memiliki intensitas aktivitas seismik yang tinggi. Aktivitas 
ini memberikan data-data kegempaan yang dapat dimanfaatkan pula untuk eksplorasi panas bumi.

Lapangan Panas Bumi ARD terletak di kabupaten Muara Enim, sekitar $225 \mathrm{~km}$ dari kota Palembang, Sumatra Selatan. Selama lebih dari enam bulan, telah dilakukan perekaman gempa mikro (mikroseismik) pada wilayah ARD. Perekaman gempa mikro pada lapangan ini dilaksanakan oleh kerjasama antara PT Supreme Energy selaku pemegang izin kerja Lapangan Panas Bumi ARD dengan pihak IESE (Institute of Earth Science and Engineering), New Zealand dengan menggunakan 26 stasiun yang telah dipasang selama 8 bulan sejak Agustus 2011 hingga Mei 2012 dengan stasiun terjauh berjarak $20 \mathrm{~km}$ dari daerah potensi sumber daya panas bumi. Terdapat 637 event gempa mikro lokal yang terdeteksi dan terpetakan. Jumlah ini cukup besar untuk sebuah daerah yang masih dalam tahap awal eksplorasi panas bumi. Daerah dengan tingkat seismisitas tinggi dapat merepresentasikan bahwa daerah tersebut memiliki rekahan dengan permeabilitas yang tinggi pula.

Akan tetapi, akurasi lokasi hiposenter gempa mikro pada lapangan ini masih dapat ditingkatkan karena beberapa faktor yang memepengaruhi, di antaranya adalah banyaknya noise pada saat proses perekaman, waktu tiba gelombang yang di-pick secara otomatis ataupun manual. Sehingga hal ini akan memberikan galat terhadap data waktu tiba gelombang, baik gelombang $\mathrm{P}$ maupun S (Ramadhan, 2015; Douglas dkk., 1997).

Oleh karena itu, diperlukan suatu teknik tambahan untuk meningkatkan akurasi dari data katalog yang disusun oleh pihak IESE. Pada penelitian ini kami menggunakan teknik korelasi silang master waveform (Mori, 2008) untuk memperbaiki kualitas picking dari waveform. Hasil korelasi silang tersebut kami gunakan sebagai input dari metode relokasi hiposenter double difference. Pada banyak penelitian sebelumnya, teknik double-difference dibantu oleh korelasi silang waveform akan menghasilkan relokasi hiposenter yang lebih akurat. Dengan menggunakan relokasi double-difference, hiposenter yang telah terelokasi ini dapat mencitrakan struktur kecepatan seismik 3D pada bawah lapangan panas bumi ARD yang kemudian akan diinterpretasi.

\section{KONDISI GEOLOGI}

Lapangan panas bumi ARD terletak di kabupaten Muara Enim, sekitar $225 \mathrm{~km}$ dari barat Palembang, Sumatera Selatan dan barat daya dari gunung api aktif Dempo. Lapangan ini dekat dengan perpotongan struktur geologi besar, Sesar Besar Sumatra dan Kaldera Semendo. Lapangan panas bumi ARD terletak pada kompleks volkanik Bukit Besar dengan litologi lava basaltik hingga andesitik, tuff, dan breksi (Amin, dkk., 1993) (Gambar 1).

Terdapat dua arah struktur yang mempengaruhi daerah penelitian ini, yaitu struktur dengan arah timur laut barat daya dan barat laut tenggara. Struktur dengan arah timur laut barat daya berkembang pada bagian tengah daerah penelitian. Sedangkan struktur dengan arah barat laut tenggara berkembang pada bagian utara daerah penelitian (Gambar 2).

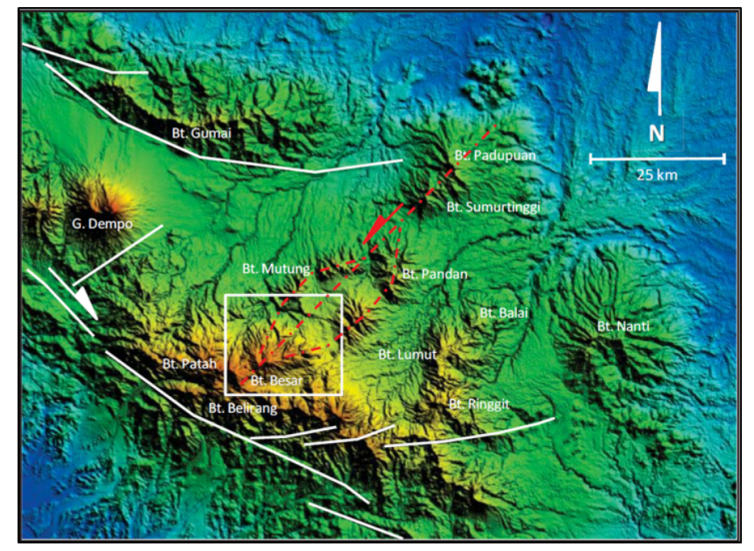

Gambar 1. Lokasi Lapangan Panas Bumi ARD (Supreme Energy, 2016)

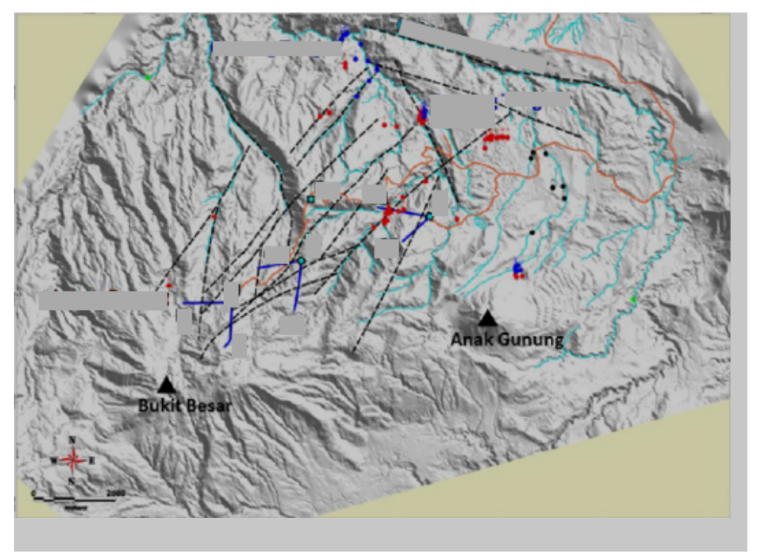

Gambar 2. Struktur geologi daerah penelitian. Secara umum terdapat dua arah struktur, yaitu arah barat laut tenggara dana rah timur laut barat daya. (Bacquet dkk., 2016) 


\section{TEORI DASAR}

\subsection{Korelasi Silang Waveform}

Dua kejadian gempa mikro yang berdekatan, dengan propagasi gelombang seismik pada lintasan yang identik akan menghasilkan waveform yang mirip pula pada stasiun yang sama. Korelasi silang gelombang yang dihasilkan oleh gempa bumi yang berdekatan yang tercatat pada stasiun yang sama dapat digunakan untuk mendeterminasi keterkaitan antara master event terhadap kejadian yang kontinu (Mori, 2008). Prinsipnya, korelasi silang dapat memperbaiki selisih waktu tempuh pasangan gempa sehingga menghasilkan lokasi gempa yang lebih akurat. $\phi_{x y} x(t) y(t)(\tau)$ pada persamaan 1 adalah korelasi silang antara dua kejadian $x(t)$ dan $y(t)$ (Havskov dan Ottomoller, 2010) dengan $\phi_{x y} \phi_{x y}(\tau)$ adalah koefisien korelasi dan adalah lag time.

$$
\begin{array}{r}
\phi_{x y}(\tau)=x(t) \circ y(t)=\int_{-\infty}^{\infty} x(t) y(t+\tau) d t \phi_{x y}(\tau) \\
=x(t) \circ y(t)=\int_{-\infty}^{\infty} x(t) y(t \tau) d t
\end{array}
$$

\subsection{Relokasi Double-Difference}

Waktu tiba $\mathrm{T}$ dari suatu gempa i yang terekam pada stasiun $\mathrm{k}$ diekspresikan dalam (Thurber dkk., 2007):

$$
T_{k}^{i}=\tau^{i}+\int_{i}^{k} u d s
$$

dengan adalah waktu terjadinya gempa $i, u$ adalah slowness dan $d s$ adalah panjang lintasan. Hubungan antara waktu tiba dan lokasi gempa sangat tidak linear, sehingga ekspansi Taylor digunakan dalam linearisasi persamaan ini. Misfit anatara waktu tiba observasi dan waktu tiba kalkulasi untuk hiposenter dan struktur kecepatan:

$$
r_{k}^{i}=\sum_{l=1}^{3} \frac{\delta T_{k}^{i}}{\delta x_{l}^{i}} \Delta x_{l}^{i}+\Delta \tau^{i}+\int_{l}^{k} \delta u d s
$$

Dengan mengurangi persamaan (3) dengan persamaan yang serupa untuk gempa j yang juga terekam pada stasiun $\mathrm{k}$ maka:

$$
\begin{aligned}
r_{k}^{i}-r_{k}^{j}= & \sum_{l=1}^{3} \frac{\delta T_{k}^{i}}{\delta x_{l}^{i}} \Delta x_{l}^{i}+\Delta \tau^{i}+\int_{i}^{k} \delta u d s \\
& -\sum_{l=1}^{3} \frac{\delta T_{k}^{j}}{\delta x_{l}^{j}} \Delta x_{l}^{j}-\Delta \tau^{j}-\int_{i}^{k} \delta u d s
\end{aligned}
$$

Asumsikan bahwa kedua gempa ini saling berdekatan sehingga ray path kedua gempa ini ke stasiun hampir sama dan struktur kecepatan diketahui, maka persamaan (4) dapat disederhanakan menjadi:

$$
\begin{aligned}
d r_{k^{i j}}=r_{k}^{i}-r_{k}^{j}= & \sum_{l=1}^{3} \frac{\delta T_{k}^{i}}{\delta x_{l}^{i}} \Delta x_{l}^{i}+\Delta \tau^{i} \\
& -\sum_{l=1}^{3} \frac{\delta T_{k}^{j}}{\delta x_{l}^{j}} \Delta x_{l}^{j}+\Delta \tau^{j}
\end{aligned}
$$

disebut sebagai double-difference (Waldhauser dan Ellsworth, 2000). Selisih hubungan waktu tiba observasi dan kalkulasi untuk dua events juga dapat ditulis sebagai berikut (Waldhauser dan Ellsworth, 2000; Zhang dan Turber, 2003):

$$
d r_{k^{i j}}=\left(T_{k^{i}}-T_{k^{j}}\right)^{o b s}-\left(T_{k^{i}}-T_{k^{j}}\right)^{c a l}
$$

\section{APLIKASI METODE KORELASI SILANG MASTER WAVEFORM}

Data yang digunakan dalam penelitian ini adalah data mikroseismik Lapangan Panas Bumi ARD selama proses eksplorasi. Lapangan ini merupakan lapangan yang relatif aktif karena terdapat 637 events mikroseismik yang terekam pada 26 stasiun selama periode 21 Agustus 2011 16 Mei 2012. Terdapat 4565 fasa $\mathrm{P}$ dan 4565 fasa $\mathrm{S}$ yang digunakan dalam penelitian ini (Gambar 3).

Pada data katalog, terdapat kualitas hiposenter yang didasarkan pada RMS residual, horizontal error, vertical error dan azimuthal gap seperti yang terlihat pada tabel 1 .

Penulis memilih master event dengan kulitas hiposenter A dengan magnitudo yang relatif besar dan memiliki waveform yang cukup jelas. Korelasi silang waveform (WCC) diolah menggunakan perangkat lunak python dengan modul obspy. Maksimum lag yang digunakan adalah 0.1 s. Kemudian, event dengan nilai koefisien korelasi diatas 0.76, waktu tiba gelombang $\mathrm{P}$ dan gelombang $\mathrm{S}$ diperbarui berdasarkan dengan koreksi pick yang dihasilkan. 
Table I . Kualitas Hiposenter (IESE, 2015)

\begin{tabular}{lcrrrrl}
\hline Quality & $\begin{array}{c}\text { RMS } \\
\text { residual (s) }\end{array}$ & $\begin{array}{r}\text { Horiz. } \\
\text { error }(\mathrm{km})\end{array}$ & $\begin{array}{r}\text { Vert. } \\
\text { error }(\mathrm{km})\end{array}$ & $\begin{array}{c}\text { Number } \\
\text { of Phase }\end{array}$ & $\begin{array}{r}\text { Azimuthal } \\
\text { gab (deg.) }\end{array}$ & $\begin{array}{l}\text { Nearest } \\
\text { station to epic }\end{array}$ \\
\hline $\mathrm{A}$ & $<0.15$ & $\leq 1.0$ & $\leq 2.0$ & $\geq 6$ & $\leq 90 \quad \leq$ depth or $\leq 5.0$ \\
$\mathrm{~B}$ & $<0.30$ & $\leq 2.6$ & $\leq 5.0$ & $\geq 6$ & $\leq 135 \quad \leq 2$ depth or $\leq 5.0$ \\
$\mathrm{C}$ & $<0.50$ & $\leq 5.0$ & - & $\geq 6$ & $\leq 180 \quad \leq 50.0$ \\
$\mathrm{D}$ & Worse than above & - & & & Worse than above \\
\hline
\end{tabular}

Terdapat 559 fasa $\mathrm{P}$ dan 527 fasa S yang diperbarui. Gambar 3 adalah contoh sebelum dan sesudah korelasi silang.

\section{RELOKASI DOUBLE DIFFERENCE DAN STRUKTUR BAWAH PERMUKAAN}

Kemudian, data katalog yang telah diperbarui digunkan untuk input program TomoDD. Dari 637 events diperoleh data waktu tempuh dengan 4065 fasa $\mathrm{P}$ dan 4065 fasa $\mathrm{S}$. Dengan menggunakan program ph2dt dihasilkan data katalog differensial

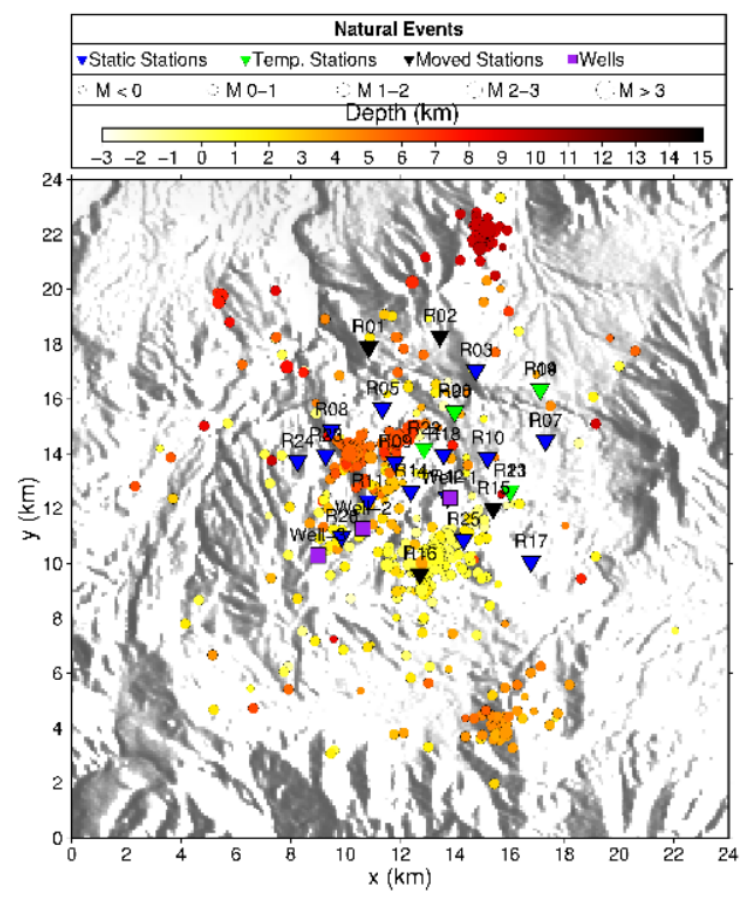

Gambar 3. Distribusi hiposenter. Stasiun digambarkan dengan segitiga terbalik. Sumur injeksi digambarkan oleh kotak berwarna ungu dan hiposenter digambarkan oleh lingkaran. Semakin besar lingkarannya, maka semakin besar magnitudonya, dan semakin gelap warna hiposer maka semakin dalam lokasi hiposenter tersebut. dengan jumlah pasangan fasa P sebanyak 21274 dan jumlah pasangan fasa S sebanyak 21273. Kedua data tersebut digunakan sebagai input relokasi double difference untuk merekonstruksi struktur seismik 3D dan relokasi hiposenter pada lapangan panas bumi ARD. Bisa dilihat pada gambar 5, bahwa proses relokasi ini berhasil memperbaiki RMS error dari lokasi hiposenter

Hasil relokasi hiposenter menggunakan metode double-difference ditunjukkan oleh gambar 6. Dapat dilihat bahwa hiposenter setelah direlokasi memiliki cluster yang lebih ketat. Selain itu, hasil root mean square (rms) dari posisi hiposenter setelah direlokasi jauh lebih baik dibandingkan dengan katalog data (sebelum relokasi).

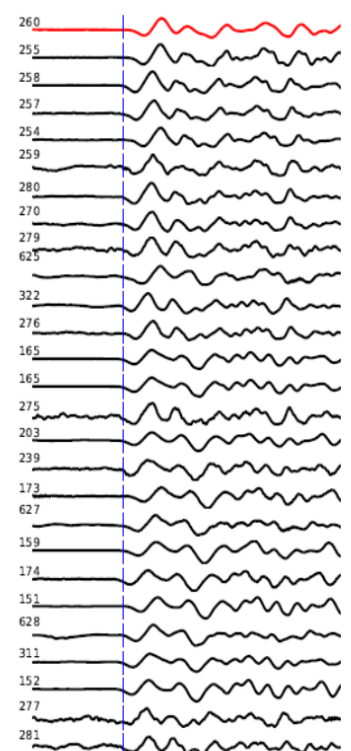

(a)

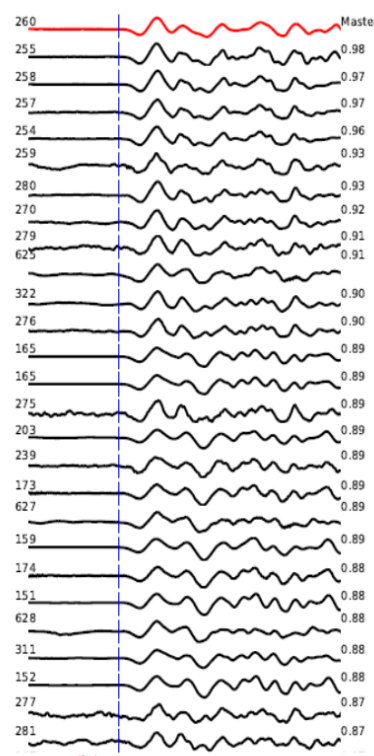

(b)
Gambar 4. Hasil korelasi silang waveform. Garis berwarna biru adalah waktu tiba gelombang $\mathrm{P}$ dan waveform yang berwarna merah adalah master event. (a) sebelum dilakukan WCC, (b) setelah dilakukan WCC. Angka disebelah kiri waveform adalah event ID, sedangkan angka disebelah kanan adalah nilai koefisien korelasi. 

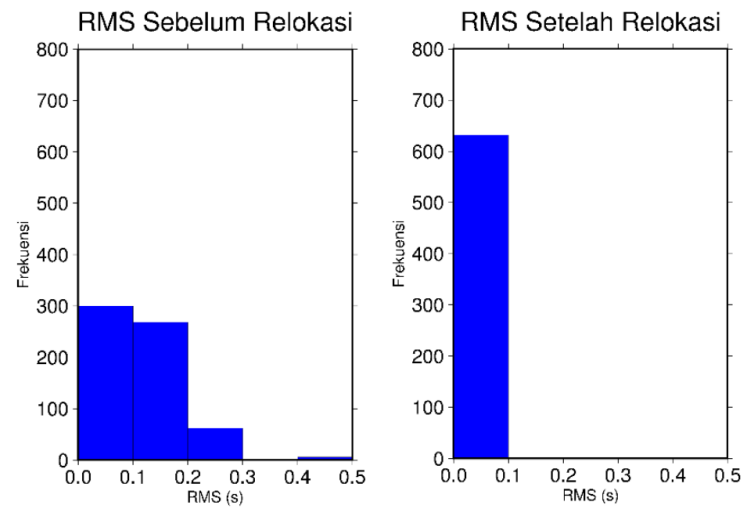

Gambar 5. Maximum tsunami amplitude distribution of the best fault model (WFM-B). Triangles represent coastal points at which tsunami waveforms are simulated.

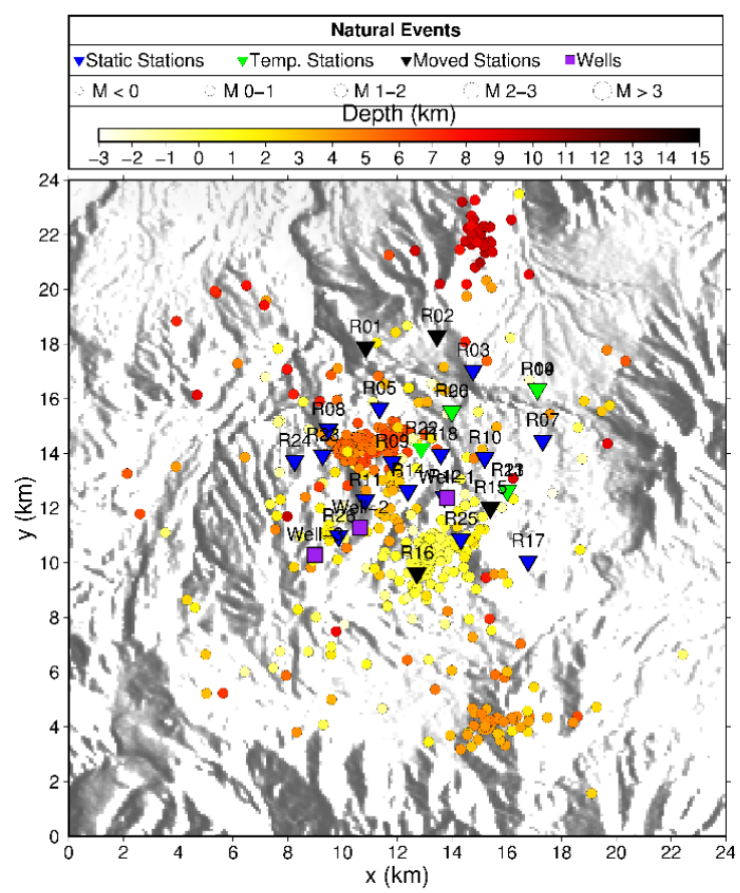

Gambar 6. Simulated tsunami waveforms at coastal points from the best westward dipping fault model (WFM-B).

\section{KESIMPULAN}

Dari hasil pengolahan data dan interpretasi, penulis mencoba menarik kesimpulan sebagai berikut:

- Dengan menggunakan metode korelasi silang master waveform, berhasil diperbaharui 559 fasa $\mathrm{P}$ dan 527 fasa $\mathrm{S}$ yang diperbarui dari 4565 fasa $\mathrm{P}$ dan 4565 fasa $\mathrm{S}$ yang tersedia.
Pada penelitian ini kami hanya menggunakan event dengan kateogori A.

- Hasil relokasi hiposenter menggunakan metode double-difference menghasilkan lokasi yang lebih akurat dengan seluruh event memiliki rms kurang dari 0.1 detik.

- Relokasi hiposenter dengan metode korelasi silang master event dan double difference berhasil mereduksi ketidakpastian lokasi hiposenter di ARD. Metode ini bisa juga diaplikasikan pada lapangan geothermal yang lain

\section{DAFTAR PUSTAKA}

Amin, T.C., Rustandi, E., Gafoer, S. Peta Geologi Lembar Manna dan Enggano, Sumatera.1993. Pusat Penelitian dan Pengembangan Geologi.

Bacquet, A., Putra, A. P., Bjornsson, G., Arnaldsson, A. Inverse Numerical Modelling of Rantau Dedap Geothermal Field after Six Exploration Wells. 2016. Proceeding 41th Workshop on Geothermal Reservoir Engineering. Standford Univerity.

Douglas, A., D. Browers, J. B. Young. On the onset of P seismograms. 1997. Geophysics Journal International 129 pp 681-690.

Havskov, J. dan Ottemoller, L. Routine Data Processing in Earthquake Seismology. 2010. Springer.

IESE. Supreme Energy Internal Report. 2015. Supreme Energy

Mori, J. Determination of Dip Direction for the 2007 Chuetsu-oki Earthquake From Relocation of Aftershocks Using Arrival Times Determined by Cross-Correlation. 2008. Earth, Planet, Space, 60, 1117-1120.

Ramadhan, I.,. Exploration Uncertainties in GSF: MT Case Study. 2015. Indonesian Conference on Geothermal Mineralogy and Volcanology.

Thurber, C., Ritsema, J. Theory and Observations Seismic Tomography and Inverse Method. 2007. Elsevier.

Waldhauser, F., Ellsworth. A Double-Difference Earthquake Location Algorithm: Method and Application to the Northern Hayward Fault, California. 2000. Bulletin of the Seismological Society of America, 90, 6, pp.1353-1368

Zhang, H., Thurber, C. H. Double Difference Tomography: The Method and Its Application to the Hayward Fault, California. 2003. Bulletin of the Seismological Society of America, 93, 5, pp.1875-1889 